\title{
Thermal characterisation of Lake Morskie Oko water in 2007 based on measurements by a gradient thermal probe
}

\author{
Adam Choiński \\ Adam Mickiewicz University, Department of Hydrology and Water Management, Dzięgielowa 27, 61-680 Poznań, Poland, \\ e-mail: choinski@amu.edu.pl
}

\begin{abstract}
The study was undertaken to illustrate a wide range of application of a gradient thermal probe in thermal characterisation of water reservoirs on the example of Lake Morskie Oko whose water temperature has been measured since 2006. For analysis, the data collected in 2007 were chosen because of the least missing data; in this year only the data from 13 days were not recorded. The data permitted analysis of changes in daily mean temperatures of water at particular depths, with the daily means calculated as arithmetic means from 144 measurements made at every 10 minutes. The daily amplitudes of temperatures at particular depths and mean daily amplitudes for particular months were determined, which permitted an assessment of the scale of the temperature amplitude damping with increasing depth. High frequency of temperature reading permitted detection of short-duration anomalies, taking place e.g. over a time span of 10 minutes, or their vertical extent. It has been established that measurement at 2 a.m. is the optimum for determination of the annual mean temperature. The time moments at which the minimum and maximum temperatures are recorded within a day at the surface were identified. Different variants of temporary jump changes in the surface water temperature within the day were analysed. The dynamics of temperature changes from the surface to the bottom of the lake was discussed.
\end{abstract}

Key words: high altitude lake, temperature profiles, Tatra Mountains

\section{Introduction}

Since June 2006 a probe has been installed in Lake Morskie Oko to measure temperatures of its water over its depth. The probe is anchored at the site at which the lake's depth reaches $50 \mathrm{~m}$. The recording device floats on the water surface supported by a buoy and is connected to temperature sensors stabilised at the depths of $1 \mathrm{~m}, 5 \mathrm{~m}, 10 \mathrm{~m}, 20 \mathrm{~m}$ and $50 \mathrm{~m}$. The temperature at each depth is measurement at every 10 minutes to the accuracy of $0.1^{\circ} \mathrm{C}$. Over the few years of the temperature monitoring the probe has been frequently out of order because of external damaging factors such as avalanches, lightning discharge, ice phenomena, intense waves, breaks in current supply etc. In this respect the year 2007 was fortunate as only for 13 days (January $1^{\text {st }}$ to $13^{\text {th }}$ ) the probe was not working. In this year over 250 thousand measurements were recorded.

Lake water temperature monitoring provides important information and does not require much in- vestment. Besides the cognitive significance the data are of practical importance as permit prediction of avalanche fall or indicate the time at which temperature measurement is closest to the daily mean. The aim of the study was to present the scope of application of the temperature probe recordings to many issues related to thermal characterisation of water.

In Poland, the thermal characterisation of lake waters with the use of a gradient probe has been hitherto made by Choiński and Łyczkowska (2008), and Łyczkowska (2009) in mountain lakes as well as by Choiński and Kanikowski (2004), and by Glazik, Marszelewski and Skowron (2006) in lowland lakes.

\section{Analysis of measurement results}

Recording of water temperature at a high frequency (e.g. at every 10 minutes) permits incomparably more accurate determination of daily mean temperatures than measurements once a day (e.g. at 7 a.m.). On the basis of the probe data the daily mean temperature 
is determined as the arithmetic mean of 144 measurements, which eliminates the random error probable to occur when only one temperature measurement per day is made. Fig. 1 illustrates the temperature changes at particular depths obtained on the basis of the probe measurements. The plots reflect the dynamics of temperature changes that can be investigated not only at the lake surface but at a few selected depths. Also the temperature changes and their tendencies can be established for longer time periods, e.g. in a month, thermal seasons in the periods of ice-cover development, etc.

The data supplied by the probe permit also determination of mean temperatures over the lake depth at a given moment. Fig. 2 presents the mean values over the whole lake depth obtained as arithmetic means of measurements performed on a given day at five depths. This curve illustrates the variation of heat resources at a given vertical profile. In the seasons of winter and spring the course of this curve is stable. Starting from the spring homothermy an increase in heat resources is clearly reflected and then from July to the autumn homothermy the heat resources gradually decrease. All irregularities in the above curve reflect not only temperature changes at the lake water surface but the character of inner circulation of deeper layers of water.

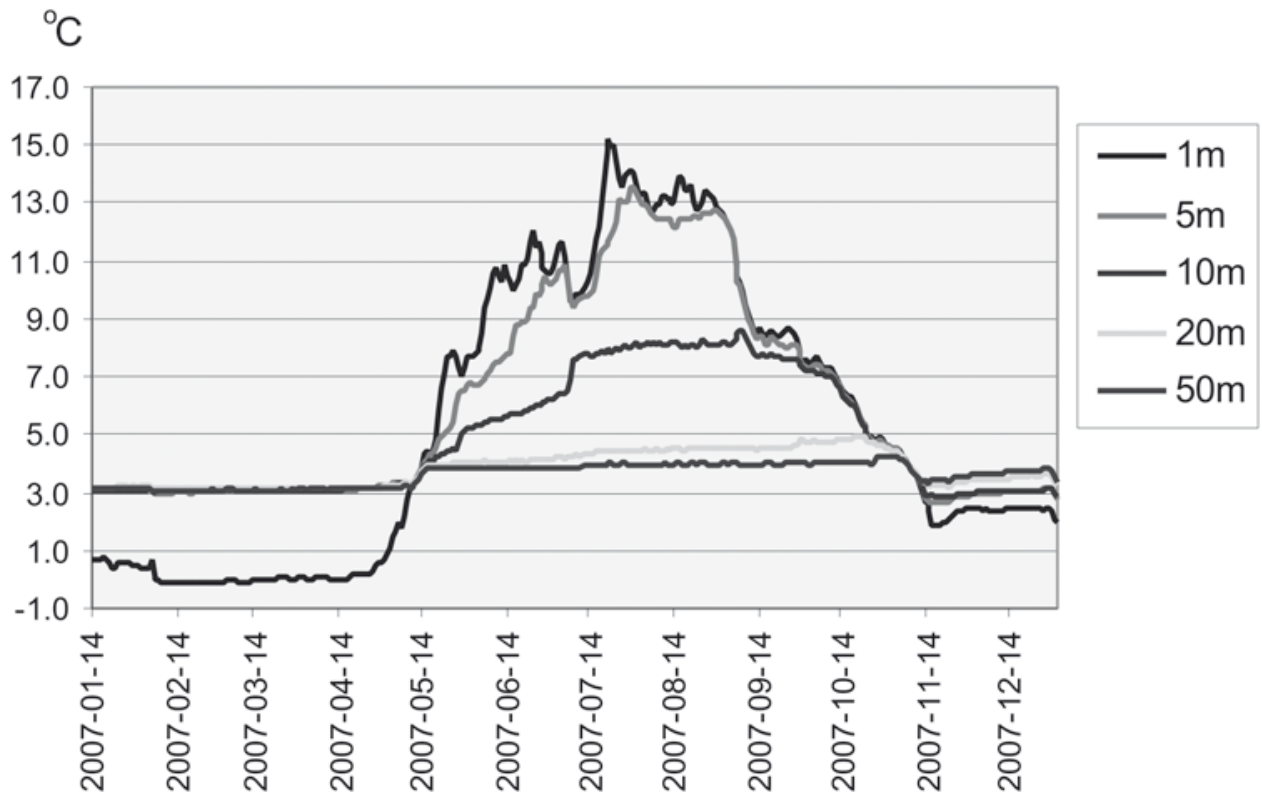

Fig. 1. Daily mean temperatures of Morskie Oko water at particular depths

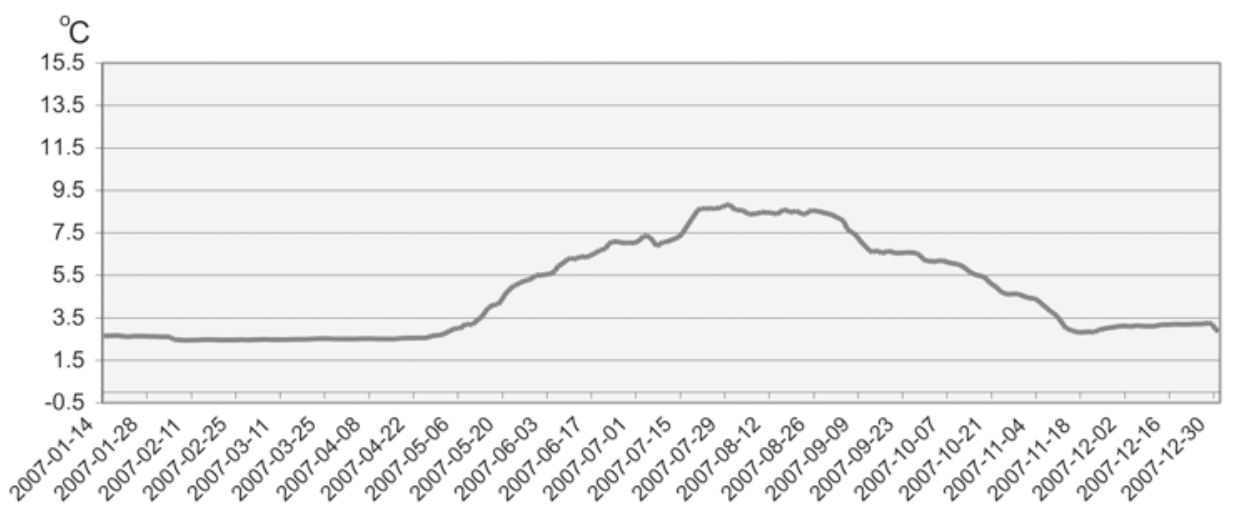

Fig. 2. Mean temperatures of the vertical profile (obtained as arithmetic means from 4 independent measurements) 
An important problem was whether the temperatures measured daily at 7 a.m. (06:00 GMT) at the water surface are reliable representatives of day average ones. The temperatures measured at 7 a.m. were compared with the daily mean temperatures calculated as the arithmetic means from the measurements recorded for the whole day. Fig. 3 presents the relevant two curves for the year 2007. The differences in the character of their courses are small but it should be noted that the daily mean temperatures calculated as the arithmetic means from the daily data are higher. It is particularly distinct from the beginning of May till the end of August, while in the period of spring and autumn circulations and winter stagnation the temperatures measured at 7 a.m. and calculated as the daily mean are similar. The annual mean temperature (for 2007) found on the basis of measurements at 7 a.m. was $5.28^{\circ} \mathrm{C}$, while on the basis of daily mean calculation it was $5.36^{\circ} \mathrm{C}$. The difference is $0.08^{\circ} \mathrm{C}$. In order to find out the hour of measurements for which the data will give the annual average closest to the annual average calculated on the basis of all measurements we compared the annual mean temperatures calculated at particular full hours to the annual average based on all measurements, see Fig. 4. As follows from this comparison, the annual mean calculated on the basis of measurements made at 2 a.m. is $5.36^{\circ} \mathrm{C}$, which is the annual average calculated on the basis of all data. Also close were the mean values calculated on the basis of measurements made at 1 a.m. and at midnight, which were both equal to $5.37^{\circ} \mathrm{C}$.

Measurements of water temperature performed at a high frequency permit determination of the maximum and minimum temperatures in a given time interval so the temperature amplitudes. The highest temperatures of $15.7^{\circ} \mathrm{C}$ at the lake surface were recorded on the $21^{\text {st }}$ and $22^{\text {nd }}$ July at 11 p.m. -0.30 a.m. and on the $24^{\text {th }}$ of July at midnight, of $15.9^{\circ} \mathrm{C}$, see Fig. 5. The temperatures measured at the standard time of measurement ( 7 a.m.) were by $0.9^{\circ} \mathrm{C}$ and by as much as $1.7^{\circ} \mathrm{C}$ lower on the corresponding days. Interestingly, such a high temperature of Morskie Oko water has not been recorded over the period of 1967-1983, in which the data were collected. It is reasonable to expect that the temperature could be even higher if the measurements were made in the coastal zone in which the standard measurements are made. Apart from the fact that it is the wind shielded zone, to this zone additional thermal energy is supplied from the surrounding rocks in contact with the lake water, in which the thermal energy is accumulated during the day.

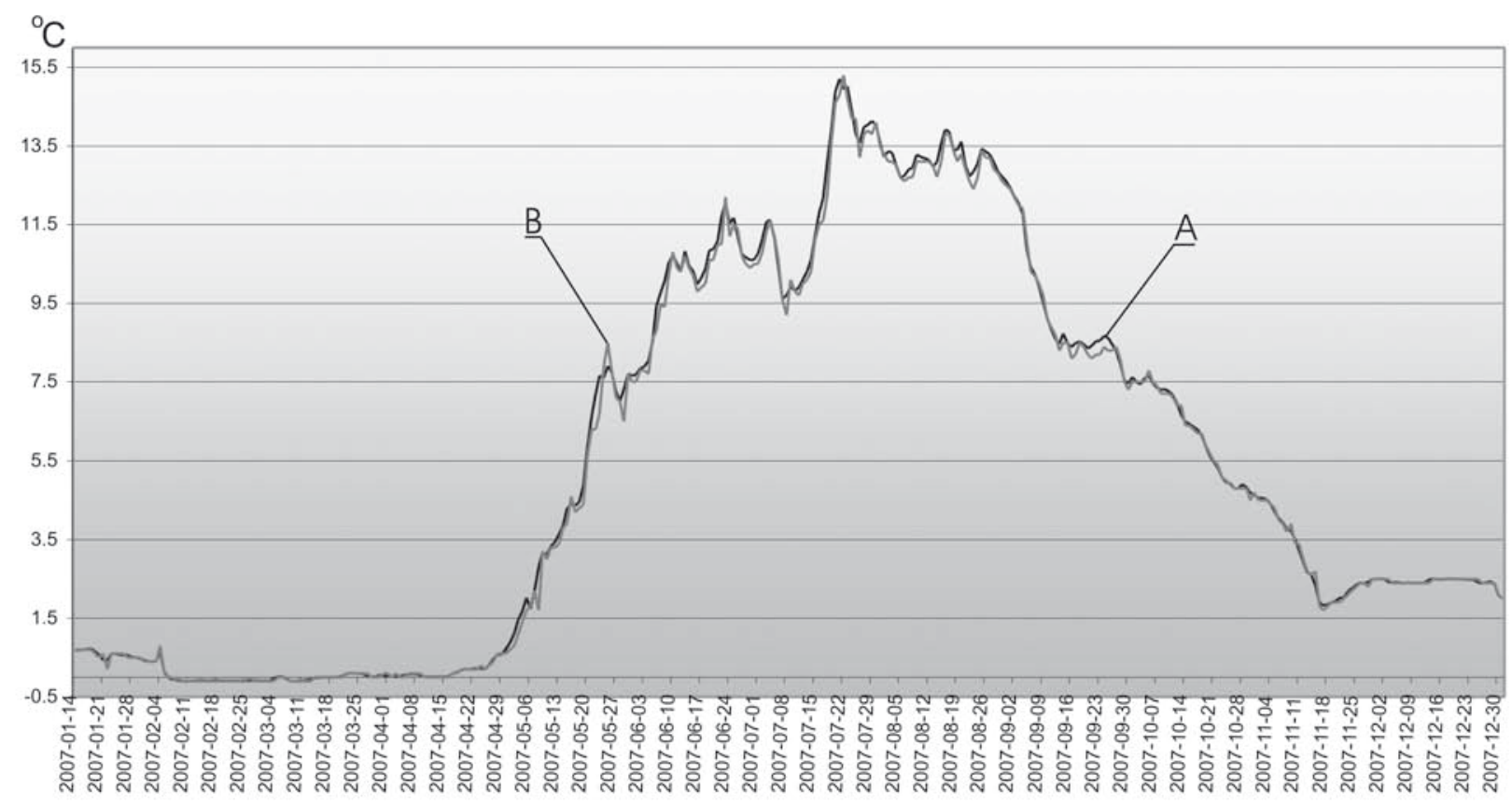

Fig. 3. Temperature changes in the near-surface water layer: A - everyday measurements at 7 a.m. B - daily mean temperatures (arithmetic means) 


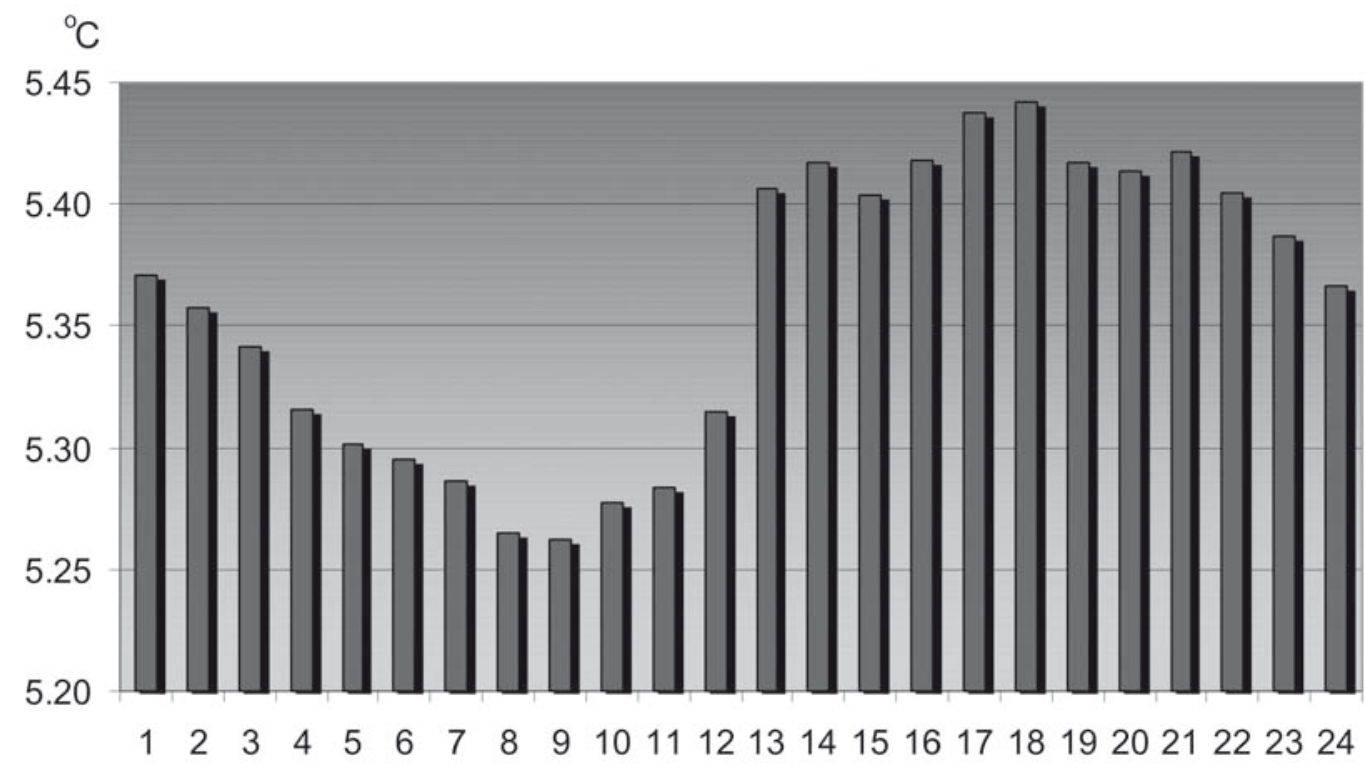

Fig. 5. Character of temperature changes near the lake surface in the period when the maximum temperatures were noted

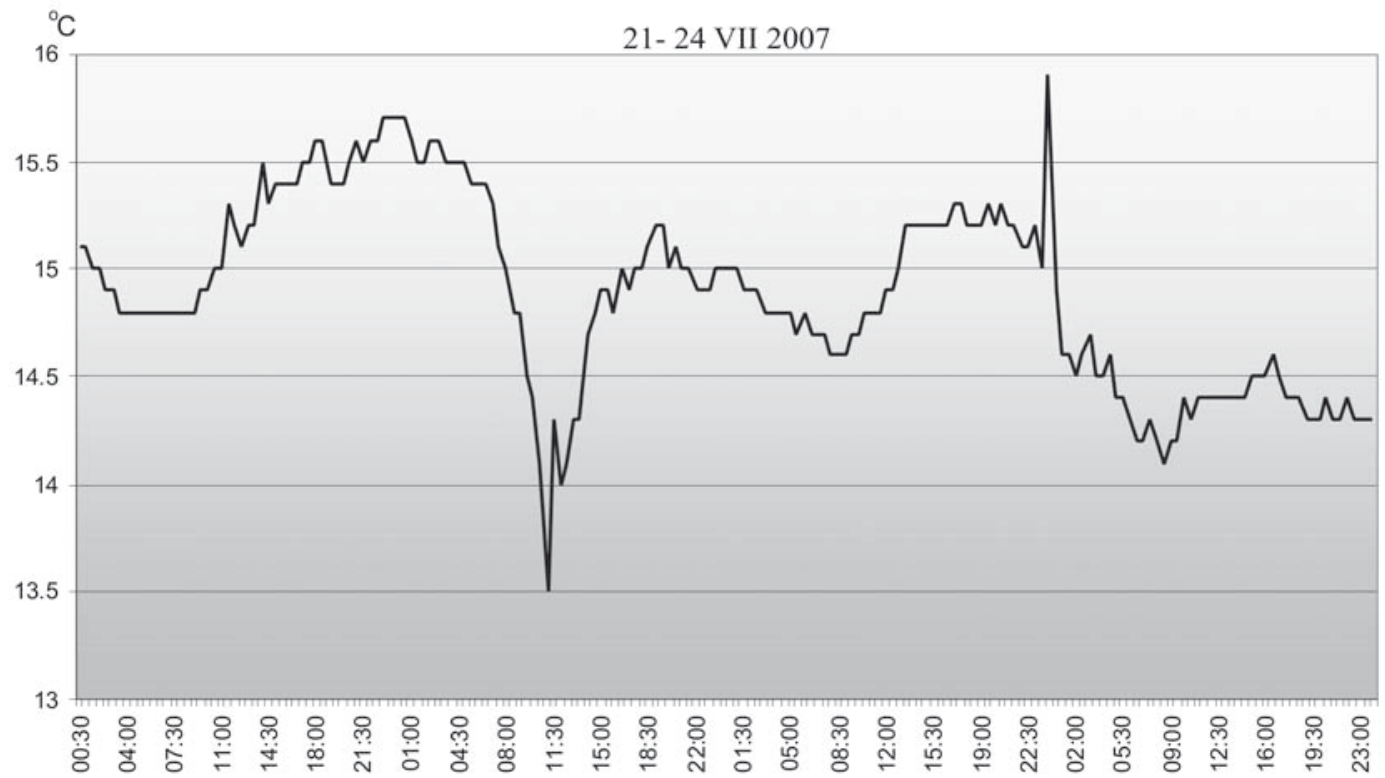

Fig. 6. The frequency of minimum (A) and maximum daily temperatures (B) (for the days on which the temperature amplitude was $\geq 1^{\circ} \mathrm{C}$ )

Another interesting information obtained from the measurement was the moments of time at which the maximum and minimum temperatures occurred. The analysis for this purpose was made for the days on which the temperature amplitude was rather significant, that is $\geq 1^{\circ} \mathrm{C}$ as when the amplitude is low, minimum and maximum temperatures can be noted a few times during the day. In the year 2007 the temperature amplitudes $\geq 1{ }^{\circ} \mathrm{C}$ were noted on 70 days (Fig. 6). As follows from the time distribution of the maximum and minimum temperatures, the minimum values can occur practically at each hour except 4 p.m., 5 p.m. and 7 p.m. Maximum temperatures were never noted at 3 a.m. and between 5 a.m. and noon. Most often the minimum temperatures were noted at 4, 7 and 8 a.m., while the maximum ones at midnight, at noon and at 5 p.m. The 
character of the above distribution indicates that the changes in the air temperature can be only one factor influencing the occurrence of minimum and maximum temperatures of the lake water. An important factor determining the distribution of temperatures can be the dynamics of water masses dependent on the strength and direction of winds and type of shielding of the lake basin. The influence of this dynamics should be analysed in a separate future study.
Determination of the minimum and maximum temperatures on particular days permitted eliciting the information on the daily amplitudes at particular depths in the period of one-year (Fig. 7). The daily temperature amplitudes are shown to decrease with increasing lake depth. A certain deviation from this tendency is the fact that relatively large temperature amplitudes were noted at the depth of 10 meters. Significant daily amplitudes (greater than $0.5^{\circ} \mathrm{C}$ per day)
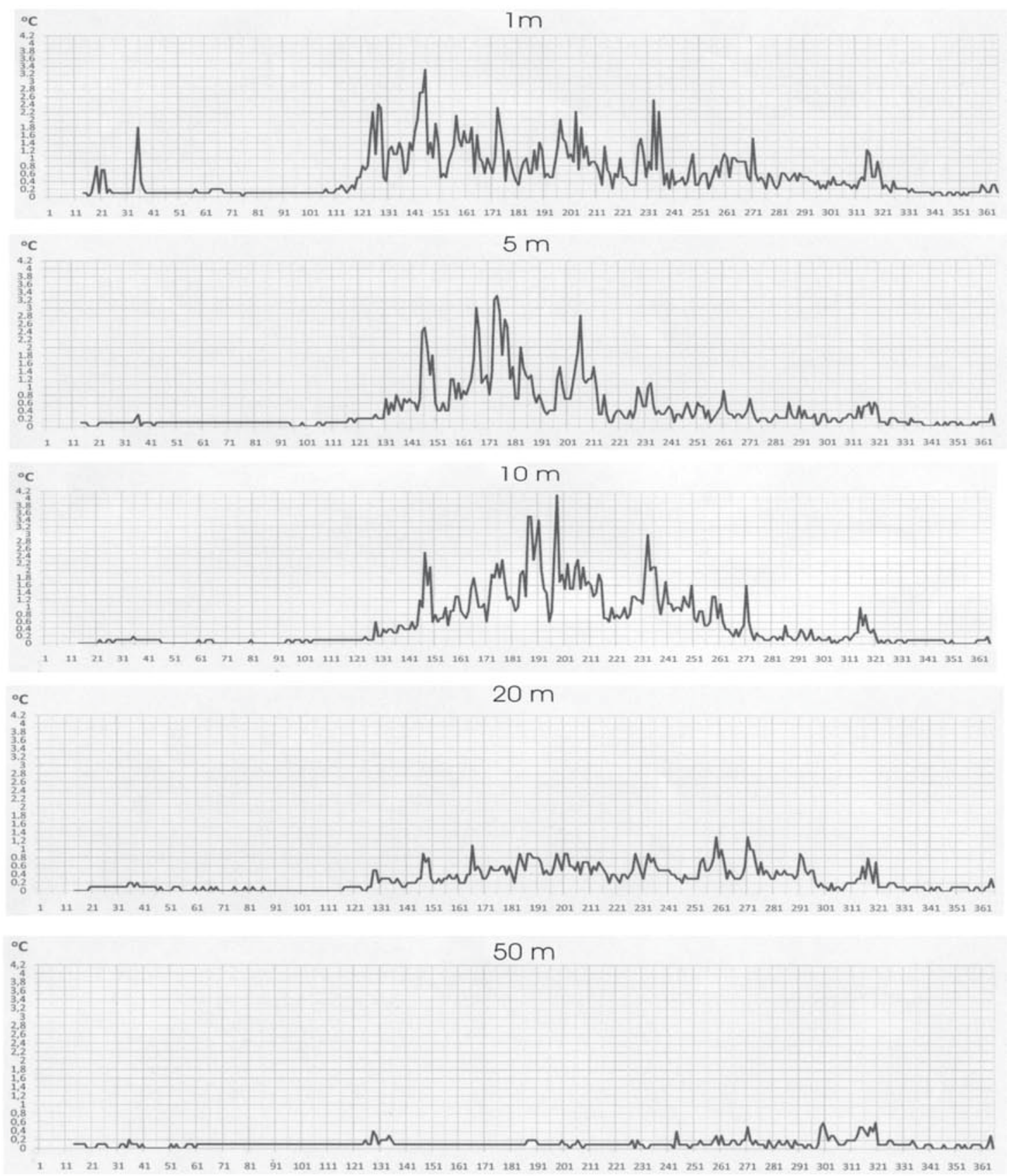

Fig. 7. The daily temperature amplitudes at particular depths 


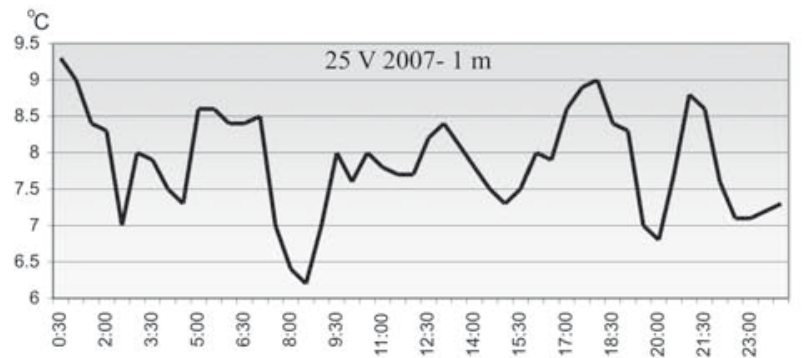

are most often noted in the near-surface water layer, everyday from May to November and sporadically in January and February. The period of occurrence of such amplitudes decreases with increasing depth and near the bottom the amplitudes are rarely noted, mainly in autumn. The peaks corresponding to high amplitudes at particular depths on certain days coincide, but on other days they are absolutely not correlated. This result indicates the presence of internal circulations of the bulk lake water in a lake part or in the entire lake.

Another interesting information provided by the data recorded was on the daily changes in the maximum amplitudes of water temperature at particular depths (Fig. 8). Interestingly, the greatest temperature amplitude of $4.1^{\circ} \mathrm{C}$ was not noted at the lake surface but at the depth of $10 \mathrm{~m}$. At the depths of 1 and $5 \mathrm{~m}$ the greatest amplitude was $3.3^{\circ} \mathrm{C}$. Much smaller amplitudes were noted in the deeper layers; $1.3^{\circ} \mathrm{C}$ at the depth of $20 \mathrm{~m}$ and $1.6^{\circ} \mathrm{C}$ at the depth of $50 \mathrm{~m}$. At particular depths the maximum daily amplitudes were observed on different dates. At the depth of $1 \mathrm{~m}$ the maximum daily amplitude was recorded in May, at $5 \mathrm{~m}$ in June, at $10 \mathrm{~m}$ in July, at $20 \mathrm{~m}$ in September and at $50 \mathrm{~m}$ in October. Most often the time span between the minimum and the maximum temperatures was of a few hours. Exceptionally, at the depth of $5 \mathrm{~m}$ the maximum daily amplitude was noted in the time span of an hour.

By summing up the daily amplitudes noted in
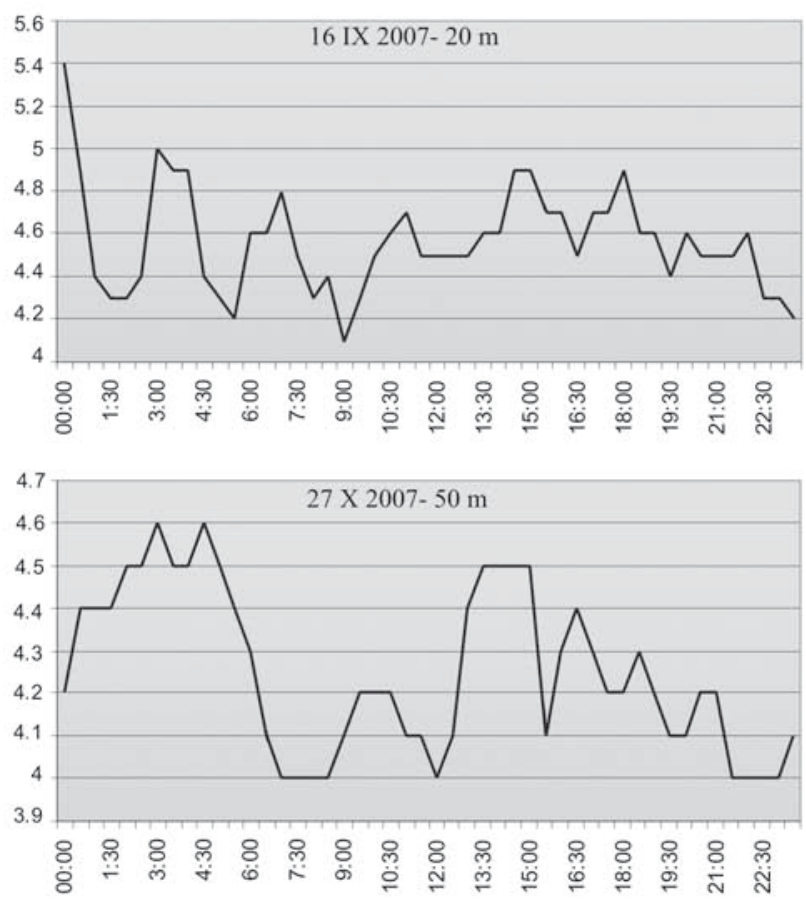

Fig. 8. Maximum daily temperature amplitudes at particular depths

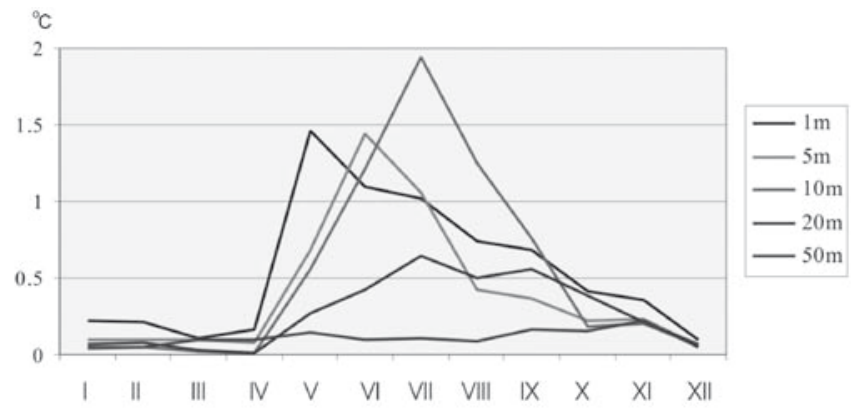

Fig. 9. Monthly mean of daily temperature amplitudes at particu-

lar depths a given month and dividing the sum by the number of days in this month the monthly means of daily amplitudes were found. The monthly means of daily amplitudes at particular depths are given in Fig. 9. From January to April the daily amplitudes were small and varied in the range $0.1-0.2^{\circ} \mathrm{C}$. From May the ampli- 
tudes increase, except for the depth of $50 \mathrm{~m}$, at which the maximum amplitude noted in November was only slightly greater than $0.2^{\circ} \mathrm{C}$. The maximum monthly means of daily amplitudes were reached at $1 \mathrm{~m}$ in May, at $5 \mathrm{~m}$ in June, at 10 and $20 \mathrm{~m}$ in July. From these maximum values the amplitudes were observed to gradually decrease till December. The maximum monthly means of daily amplitudes at particular depths were: at $1 \mathrm{~m}-1.46^{\circ} \mathrm{C}$, at $5 \mathrm{~m}-1.44^{\circ} \mathrm{C}$, at $10 \mathrm{~m}-1.94^{\circ} \mathrm{C}$, at $20 \mathrm{~m}-0.64^{\circ} \mathrm{C}$ and at $50 \mathrm{~m}-0.22^{\circ} \mathrm{C}$. The surprising observation is that the maximum amplitude occurred at the depths of $10 \mathrm{~m}$.

Continuous recording of the lake water temperature (a few measurements per hour over a few years) also permits analysis of temporary jump changes in the water temperature in a day. Fig. 10 presents six examples of such changes noted in the near-surface layer. The changes not always follows the generally accepted scheme of increasing temperature from the morning to the afternoon and then its decrease. This course of changes was observed on the $7^{\text {th }}$ of May and $6^{\text {th }}$ of June 2007, when a significant increase in temperature was observed from the noon. According to the data from the $23^{\text {rd }}$ of May, the temperature was increasing from 5 a.m. till 10 p.m. For the $24^{\text {th }}$ and $25^{\text {th }}$ of May it is difficult to conclude about any tendency of temperature changes as the corresponding curves show a number of irregular jumps at different hours. The data for the $22^{\text {nd }}$ of June show an increase in temperature from 5 a.m. to 7 p.m. and then its rapid decrease followed by a rapid increase starting at 8 p.m. and lasting till midnight. Momentary sometimes high jumps in the temperature of surface water are noted at practically all hours of the day. The jump changes result on the one hand from the absorption of sunlight energy and on the other hand from the water circulation leading to water mixing. Moreover, intense precipitations can have considerable effect on temperature of the lake surface water. According to the data collected, the jumps can be really significant: within an hour the temperature difference can reach from 1 to $3^{\circ} \mathrm{C}$, depending on the day. The greatest temporary temperature increase of as much as $2.9^{\circ} \mathrm{C}$ was observed to take place within $10 \mathrm{~min}$ on the $24^{\text {th }}$ of May.

The next problem considered was the optimum time interval of data recording. Increased frequency of data recording would bring increased use of energy and probe memory. It reasonable to suppose that the optimum frequency depends on the dynamics of temperature changes. Fig. 11 presents exemplary plots il-

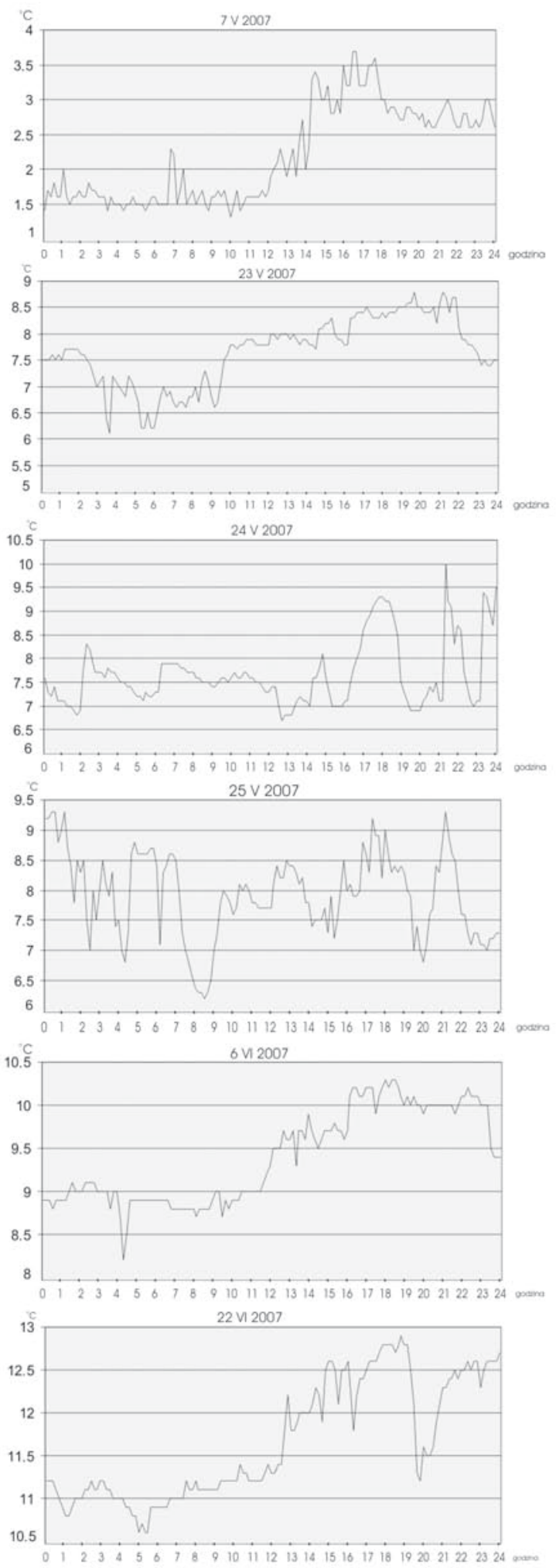

Fig. 10. Exemplary temporary significant jumps in temperature of the lake water at the depth of $1 \mathrm{~m}$ 

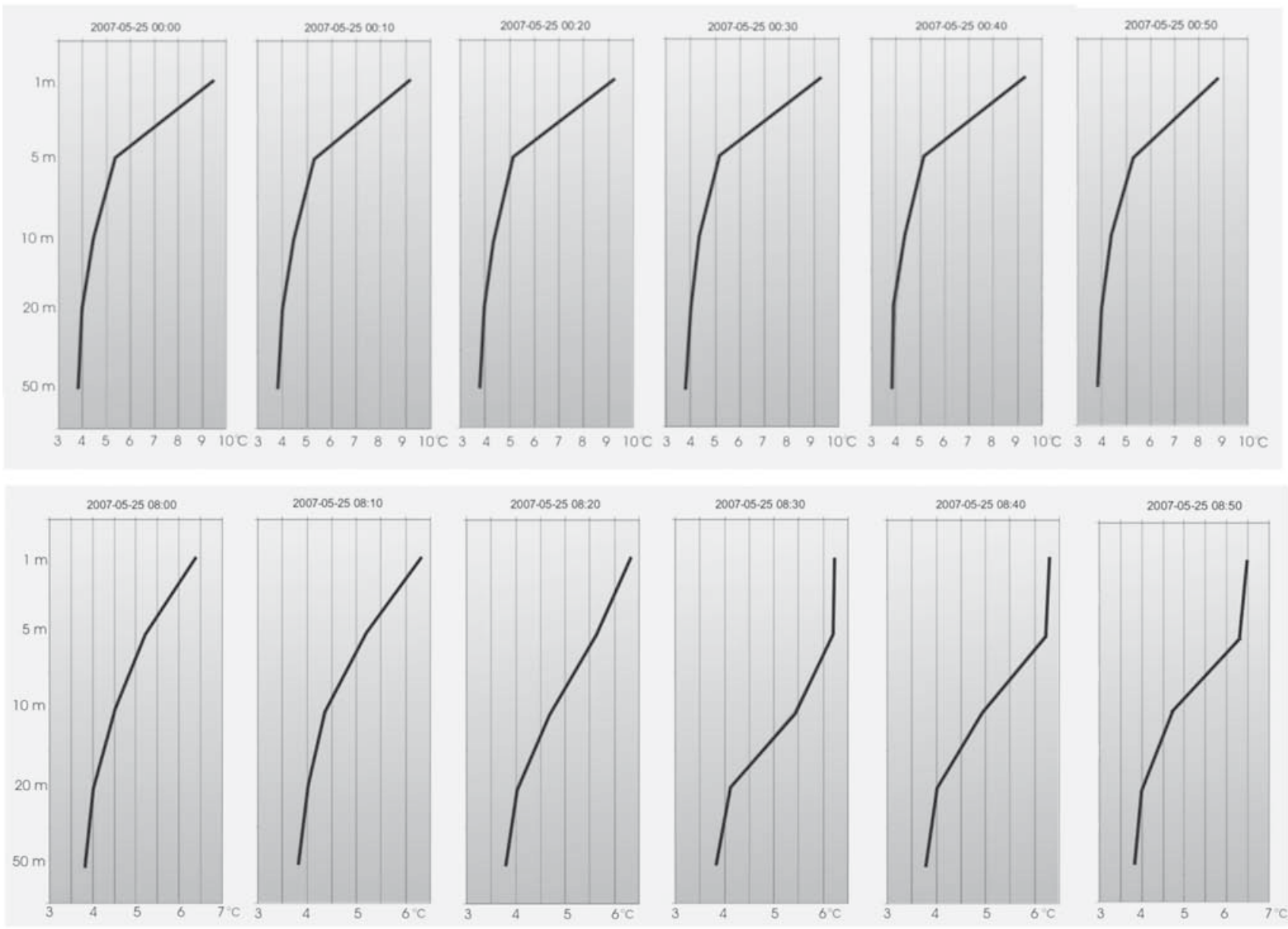

Fig. 11. Exemplary distribution of temperatures measured along the vertical profile at intervals of 10 minutes

lustrating changes in the lake water temperature along the depth measured at every $10 \mathrm{~min}$. The upper plot corresponds to stable conditions, while the bottom plot to thermal instability reaching the depth of $10 \mathrm{~m}$. The temperature changes taking place within $10 \mathrm{~min}$ are significant as at the same depths can exceed even $0.5^{\circ} \mathrm{C}$. Thus, it seems recommendable to reduce the time interval between the recordings to be able to follow the changes from the moment of their appearance to disappearance.

The graphical approach applied above illustrates the temperature changes taking place in the vertical profile in a static way. A more dynamic approach has been adapted in Fig. 12 and 13. In Fig. 12 the lines correspond to time changes in temperature at particular depths, while in Fig. 13 the character of changes is given by thermoisoplets. The course of the curves is very complex. Often it is observed that an increase in temperature at a given depth is accompanied by an increase in the temperature of a deeper layer, however, sometimes the inversed situation takes place. It also happens that temperature changes are not noted at the lake surface but occur at certain depths. Only the near-bottom zone can be treated as thermally stable as the changes noted there are of the order of a fraction of degree Celsius. The above plots give an idea of the complexity of bulk water circulation and it should be remembered that they were made on the basis of the data recorded just within a few hours. In future it would be much desirable to interpret the temperature data together with those describing the water circulation coupled with the effect of the winds on the lake water surface. 


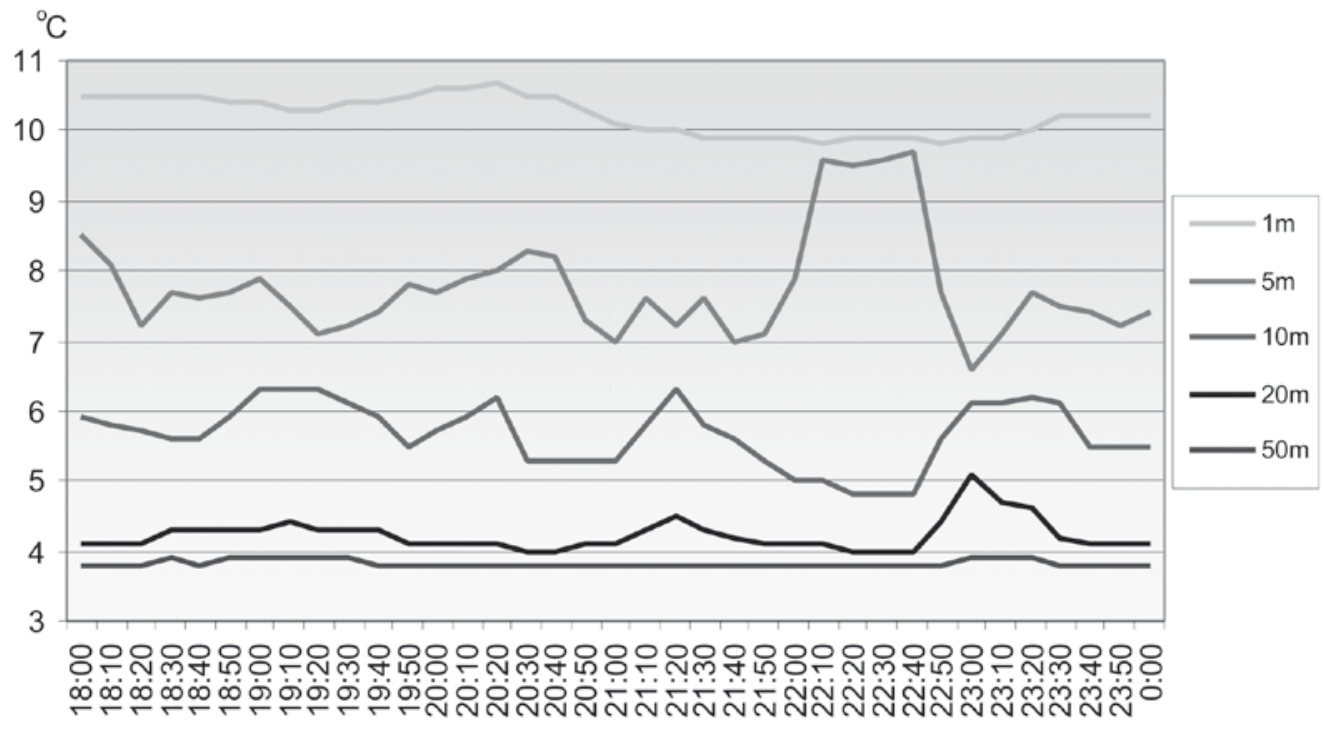

Fig. 12. Exemplary distribution of temperatures of Lake Morskie Oko water at particular depths made on the basis of measurements made at the interval of 10 minutes on the $15^{\text {th }}$ of June 2007 over the period from 6 p.m. to the midnight

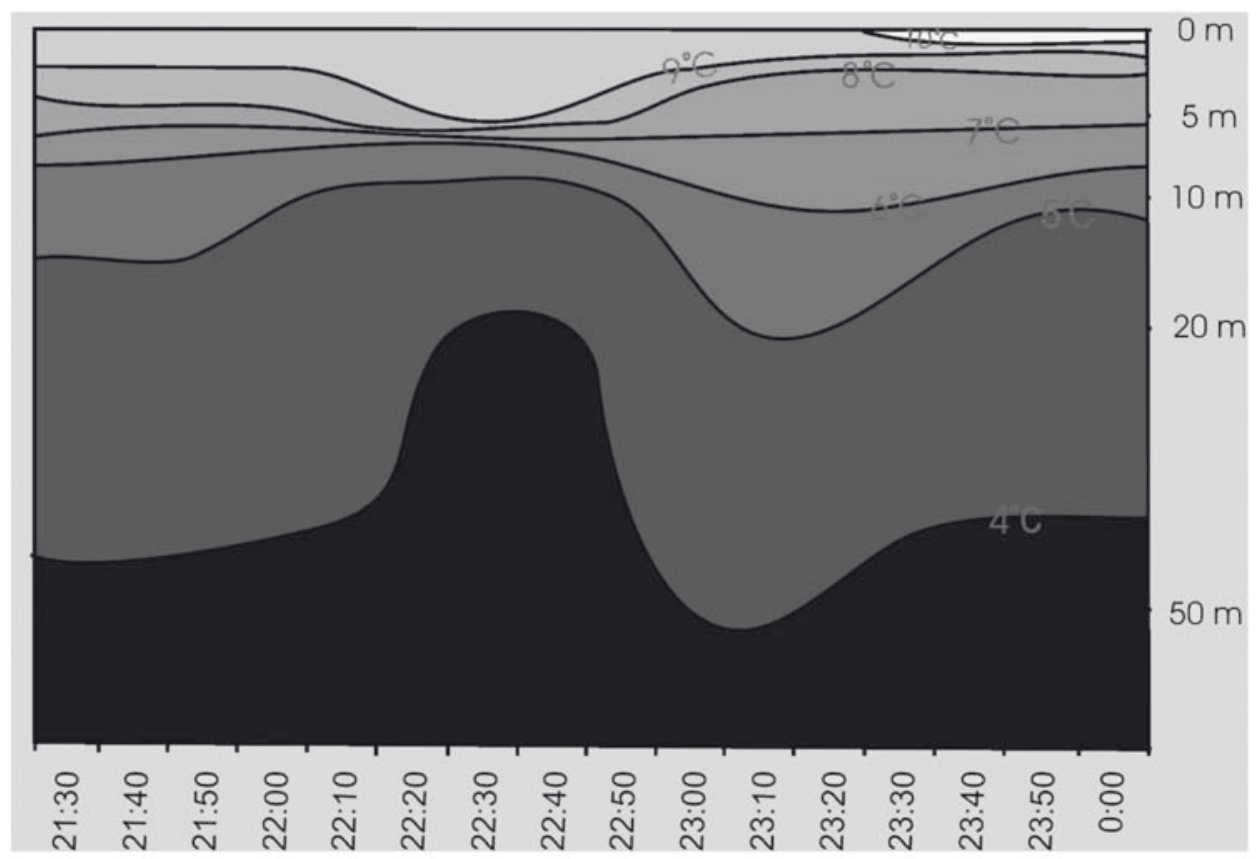

Fig. 13. Thermoizoplets of Morskie Oko water obtained on the basis of measurements made at the interval of 10 minutes on the $15^{\text {th }}$ of June 2007 over the period from 9 p.m. to the midnight 


\section{Concluding remarks}

The use of a gradient thermal probe for monitoring of lake water temperature at different depths along the vertical profile of $50 \mathrm{~m}$ provided great amount of interesting data. In future the parameters of the probe operation such as the number of data, frequency of their collection and their accuracy can be varied in a wide range. The paper illustrates the wide range of application of the data recorded by the probe for thermal characterisation of water. The data provided by the probe in the measuring regime applied were found suitable for the following purposes.

" More accurate determination of the daily mean temperature than that of the standard measurements,

»Determination of the mean temperature of water in the vertical profile at a given moment,

» Recommendation of the hour of the temperature measurements on the basis of the closest agreement with the annual mean temperature,

»Determination of e.g. daily maximum temperatures that significantly differ from those from standard measurements at 7 a.m.

"Identification of the time moments of the daily maximum and minimum temperatures

» Determination of the daily amplitudes at particular depths and the degree of their damping with increasing depths on the basis of extreme temperatures,
» Determination of monthly mean temperature amplitudes at particular depths,

» Determination of various origin temporary jumps in water temperature within days,

»Determination of the dynamics of thermal changes (stability) along the vertical profile,

Moreover, time changes in the isotherms well illustrate the water circulation between the bottom and surface.

It should be expected that in the near future the probes of this type will replace the manual measurements performed hitherto. The large number of data will certainly help comprehensive recognition of the phenomena studied and permit their more reliable interpretation.

\section{References}

Choiński A., Kanikowski J., 2004, Fluctuations in water temperature of Lake Zamkowe, Limnol. Rev. 4: 33-44.

Choiński A., Łyczkowska G., 2008, Thermal characteristics of water of Wielki Staw in the Karkonosze Mountains and Morskie Oko in the Tatras, July 2006, Pol. J. Environ. Stud. 7(5): 835-840.

Glazik R., Marszelewski W., Skowron R., 2006, Selected problems of registration of vertical distribution of water temperatures in lakes, Limnol. Rev. 6:103-110.

Łyczkowska G., 2009, Termika wód Wielkiego Stawu w Karkonoszach (Water temperature of Wielki Staw in the Karkonosze Mountains), Wyd. Nauk. UAM, Poznań:1-136 (in Polish). 